\title{
Adaptive E-Learning System Based On Learning Interactivity
}

\author{
Mohammed Yaqub ${ }^{1}$, A. M. Raid ${ }^{2}$, Haitham A. EL-Ghareeb ${ }^{3}$ \\ ${ }^{1}$ Information Systems Department, Faculty of Computers and Information Sciences, Mansoura University, Egypt \\ ${ }^{2,3}$ Faculty of Computers and Information Sciences, Mansoura University, Egypt \\ E-mail: 'yaqubmoha@gmailcom, 2amriad2000@mans.edu.eg,3helghareeb@mans.edu.eg
}

\begin{abstract}
In this paper we propose an improved E-Learning Social Network Exploiting Approach based on clustering algorithm and graph model, which can automatically group distributed e-learners with similar interests and make proper recommendations, which can finally enhance the collaborative learning among similar elearners. Through similarity discovery, trust weights update and potential friends adjustment, the algorithm implements an automatic adapted trust relationship with gradually enhanced satisfactions.
\end{abstract}

Keywords: Social Network, E-learning, Collaborative Learning, Relations, Clustering and Adpative Elearning.

\section{INTRODUCTION}

Learning is an active transaction between people as one person teaches and another learns. It is a shared experience because students explore new areas of knowledge together in such a way as to create a common core and concepts. Moreover, it is a common experience as student sacquire the same intellectual perspectives of certain learning areas.

A social network approach to learning becomes important as it provides methods and measures to assess what is exchanged, shared, delivered and received among members of a network. It also makes possible to examine outcomes such as interpersonal ties, comprise learning relationships. Conducting effective eLearning in the age of Social Media is not without its problems. E-learning has emerged as an answer to provide freedom for learners from the highly controlled environment of traditional learning. However, E-Learning is not yet that competatively efficient. It has many drawbacks like its lack of peer interaction.

It is the point that emphasizes contrast between student freedom and teacher control, which is amplified by social media. With the contrast created, teacher cannot fully control the way of learning anymore. Teacher can only influence students toward the best learning experience.
E-learning is structured learning conducted over an electronic platform. But can generally be broken down into two categories: synchronous and asynchronous, Synchronous e-learning occurs in real time with participants actively communicating with each other. Synchronous e-learning might be conducted by way of a webinar or a tele-video conference, Asynchronous e-learning does not occur in real time. Usually it involves an interactive learning tutorial or information database posted online and accessible at participants' own convenience.

E-Learning which breaks the traditional classroom based learning mode enables distributed e-learners to access various learning resources much more convenient and flexible. However, it also brings disadvantages due to distributed learning environment. Thus, how to provide personalized learning content is of high priority for e-learning applications. An effective way is to group learners with similar interests into the same community [1].

Through strengthening connections and inspiring communications among the learners, learning of the whole community will get promotion. To achieve a better performance and a higher scalability, the organizational structure of the community would better be both self organizing and adaptive [2]. 
Based on the investigation on the behavior of real students, we found out that learners have strengthened trusts if they always share common evaluations or needs of learning re- sources [3].

In this paper, we present an improved E-Learner communities self-organizing algorithm relying on the earlier work by F. Yang [4]. The algorithm uses corresponding feedback to adjust relationships between learners, aiming to find similar learners and provide facilities in their collaboration.

\section{RELATED WORK}

Many sophisticated algorithms and frameworks were designed to describe e-learning such as:

- Web-CT

- Blackboard

- Top-Class

Software from Blackboard is used to create virtual learning environment (e-learning) which provides the foundation for designing a complex and dynamic learning community. The new theoretical perspectives for Internet-based learning are quickly expanding the boundaries and structures for the on/off campus learning process [5].

For instance, the design and implementation of an Internet supported collaborative learning environment at Huddersfield University Business School needs Web based applications software to achieve an open and flexible approach which allows the transferability and integration of diverse software products. The software product Course Info, from Blackboard Inc, is used to achieve this end. Scalability and ease of integration into a campus-wide environment are the primary differentiating features of implementing a Blackboard solution, for Huddersfield University Business School are [6].
But many other systems, such Moodle, create adaptive e-learning to create the best possible learning experience for students. Technologies that adapt and shape teaching to the needs of the individual students are used to achieve this goal.

The four steps as the general data mining process are similarly applied in the process of applying rule mining over the Moodle data see ( Figure 1). These steps are outlined below:

- Collect data. The LMS system is used by students and the usage and interaction information is stored in the database. We are going to use the students' usage data of the Moodle system.

- Preprocess the data. The data are cleaned and transformed into a mineable format. In order to preprocess the Moodle data we used the MySQL System Tray Monitor and Administrator tools [7] and the Open DB Preprocess task in the Weka Explorer.

- Apply association rule mining. The data mining algorithms are applied to discover and summarize knowledge of interest to the teacher.

- Interpret, evaluate and deploy the results. The obtained results or model are interpreted and used by the teacher for further actions. The teacher can use the discovered information for making decision about the students and the Moodle activities of thecourse in order to improve the students' learning [8].

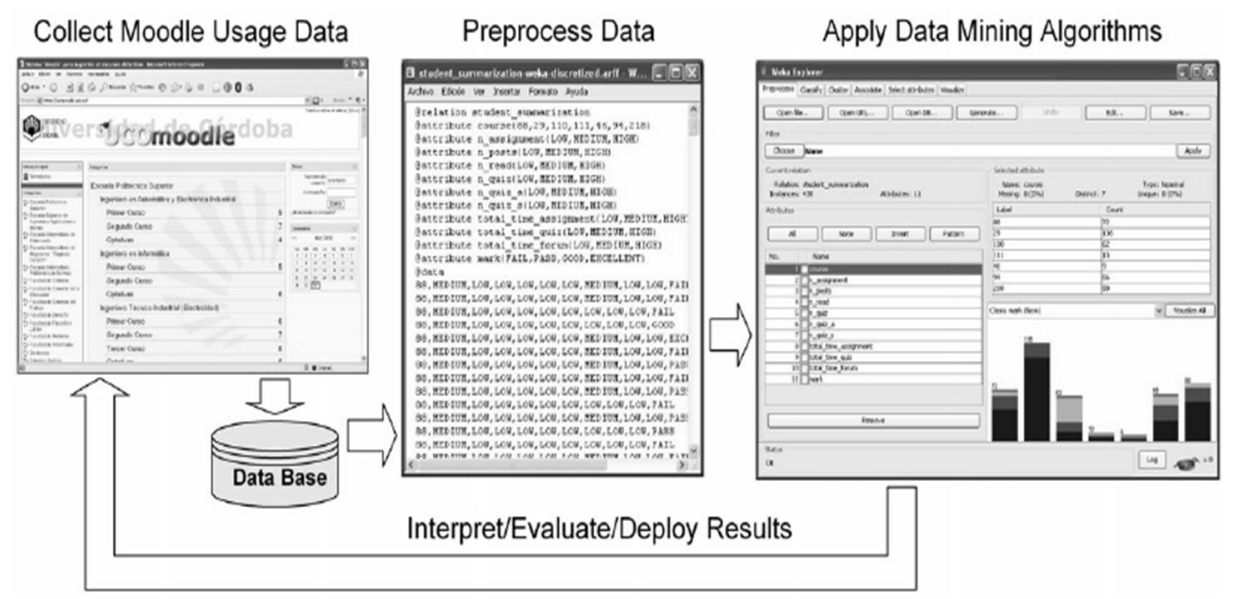

Fig. 1. Mining Moodle data 
The Original data cannot be used by a particular data mining algorithm or framework unless be transformed into suitable shapes by Data preprocessing. But before applying a data mining algorithm, a number of general data preprocessing tasks has to be solved such as data cleaning, user identification, session identification, path completion, transaction identification, data transfor-mation and enrichment, data integration, data reduction, Data preprocessing of LMS generated data has the following issues [9]:

- Moodle and most of the LMS use user authentication (password protection) in which logs have entries identified by users since the users have to log-in, and sessions are already identified since users may also have to log-out. So, we can remove the typical user and session identification tasks of preprocessing data of web-based systems.

- Moodle and most of the LMSs record the students' usage information not only in log files but also directly in relational databases.

Moreover, an Adaptive E-Learning Platform allows teachers to monitor their students' learning for the lessons they've created. Online analytics proves to be highly practical when dealing with what students know, what misconceptions they may have, and how they are interacting with content. Teachers, as such, can continuously adapt and improve their lessons. Moodle framework is highly reliable and encourages students with semantic and other motivated courses by using adaptive elearning. But it lacks the feature of social interaction especially when it comes to interact with teachers and the meaning of sharing experience [10].

General Architecture of adaptive e-learning, in this part, we present various diagrams of application design for an adaptive e-learning shown in (Figure 2). The objective is to conceive a system which can model the description of pedagogic resources and guide the learner in his formation according to his assets and to the pedagogic objective that is defined by the trainer. This pedagogic objective presents the capacities that the learner must have acquired at the end of the formation activity.

Part (1) is the Learner Space (fig.2) performs the following jobs: it accommodates the identifiers of a learner, selects his profile from the Learners database and returns it to the adapter as well as the goal of this formation. The adapter (adaptation process) uses optimization algorithms to seek the optimal strategy while selecting the courses in the resources base and provides them to the user interface. The Learner database contains the identifiers of the learner and his knowledge or asset. As a result, the system provides an optimal courses list to achieve the current goal by applying the genetic algorithms to seek the intermediate states [11].

Part (2) is the Expert Space which relates to the modelization of pedagogic resources to prepare them to be used by the adapter. In Expert Space, nominally the teacher or the expert, who seeks to integrate new resources in the base, describes them by filling a form [11].

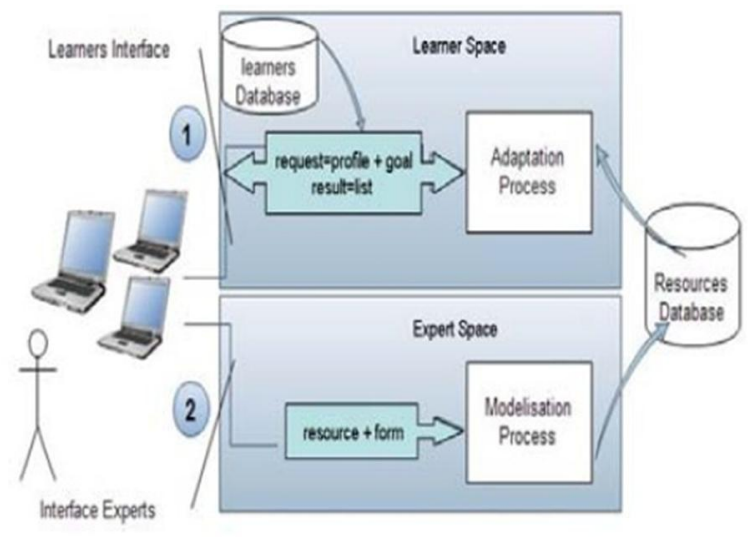

Fig. 2. Structure of the adaptive e-learning system

Such systems normally employ a relational database in order to store the large data log of the students' activities and usage information. But these systems, sometimes, make it difficult for the teacher to extract useful information due to the huge increase in the number of students and amount of information reported in spite of the fact that some platforms offer reporting tools. Recently, some researchers propose using data mining techniques in order to help the tutor in this task . Data mining techniques can be applied to analyzing student's usage data in order to identify useful patterns and to evaluate web activity to get more objective feedback for instruction and more knowledge about how the students learn on the LMS [12].

A data mining algorithm identifies knowledge via different representation models and techniques from two different inductive perspectives.

- Predictive induction, which aims at discovering knowledge for classification or prediction (Michie, Spiegelhalter \& Taylor) and clustering (Han, Kamber \& Tung) are data mining tasks under the predictive induction approach. 
- Descriptive induction, which extracts interesting knowledge from data, notably, the discovery of association rules following an unsupervised learning model (Agrawal, Imielinski, \& Swami).

One of the best studied descriptive data mining methods is the association rule mining. It seeks to discover descriptive rules about relations between attributes of a set of data which exceeds a userspecified confidence threshold, i.e., each rule must cover a minimum percentage of the data. Such rules relate one or more attributes of a dataset with another attribute, producing a hypothetical if-then statement on attribute values. Mining association rules between sets of items in large databases was first proposed by Agrawal, Imielinski, and Swami (1993) and it opened up a brand new family of algorithms. The original problem came from the failure to perform the market basket analysis which attempted to find all the interesting relationships between products bought in a given context. Association rule mining was proposed for LMS in order to identify which contents students tend to access together, or which combination of tools they use [13].

Most frameworks tend to use general e-learning categories: LMS (learning management systems) UMIS (university management information systems). These frameworks are not efficient in adequately modelling sociality and personalization between distributed learners. They also suffer many limitations with broad standard e-learning such as [14]:

- Unmotivated learners or those with poor study habits may fall behind

- Standard learning without motivation or semantic learning

- Managing learning software can involve a learning curve

- Lack of familiar structure and routine may take getting used to

- Students may feel isolated or miss social interaction

- Instructor may not always be available on demand
- Slow or unreliable Internet connections can be frustrating

Adaptive Web-based Educational systems (AWBES), a recognized class of adaptive Web systems [15] work against the "one size fits all" approach to E-Learning. After almost 8 years of research on adaptive E-Learning, encouraging results appeared [16]. Adaptive textbooks designed with InterBook [17], NetCoach [18] or ActiveMath [19] can give better and faster learning resukts. Adaptive quizzes developed with SIETTE can assess students' knowledge more precisely with fewer questions. Intelligent solution analyzers are more efficient when it comes to diagnose solutions of educational exercises and help the student to resolve problems. Adaptive class monitoring systems are more efficient in the field of monitoring students who are lagging behind. Adaptive collaboration support systems [20] highly improves the quality of collaborative learning.

The new generation of tools almost solved the traditional problems involved in adaptive learning content. However, the problem of the current generation of AWBES lies in their architecture, not performance. Structurally, modern AWBES are not that efficient in meeting the needs of learning process, especially those of the teacher and the student. Major among the drawbacks of this system are the lack of integration and availability and the lack of re-use and re-shares support [21].

\section{PROPOSED FRAMEWORK AND ALGORITHMS}

\subsection{Proposed Framework}

In order to overcome the problem of traditional elearning or adaptive e-learning, we proposed the social e-learning framework with some new features. These new features are the agent feature, the collaborative feature and semantic support feature. Agent feature, where each agent in the community holds a set of resources such (Profiles, Friendship, Courses and Exams) which are rated by proposed algorithm. Collaborative feature, each user (student and teacher) has own sharing and chatting tool which introduce availability. Semantic Support feature, each student or teacher has supported with intelligent process which suggest the closest courses and friends. (Figure 3) shows proposed social e-learning framework. 


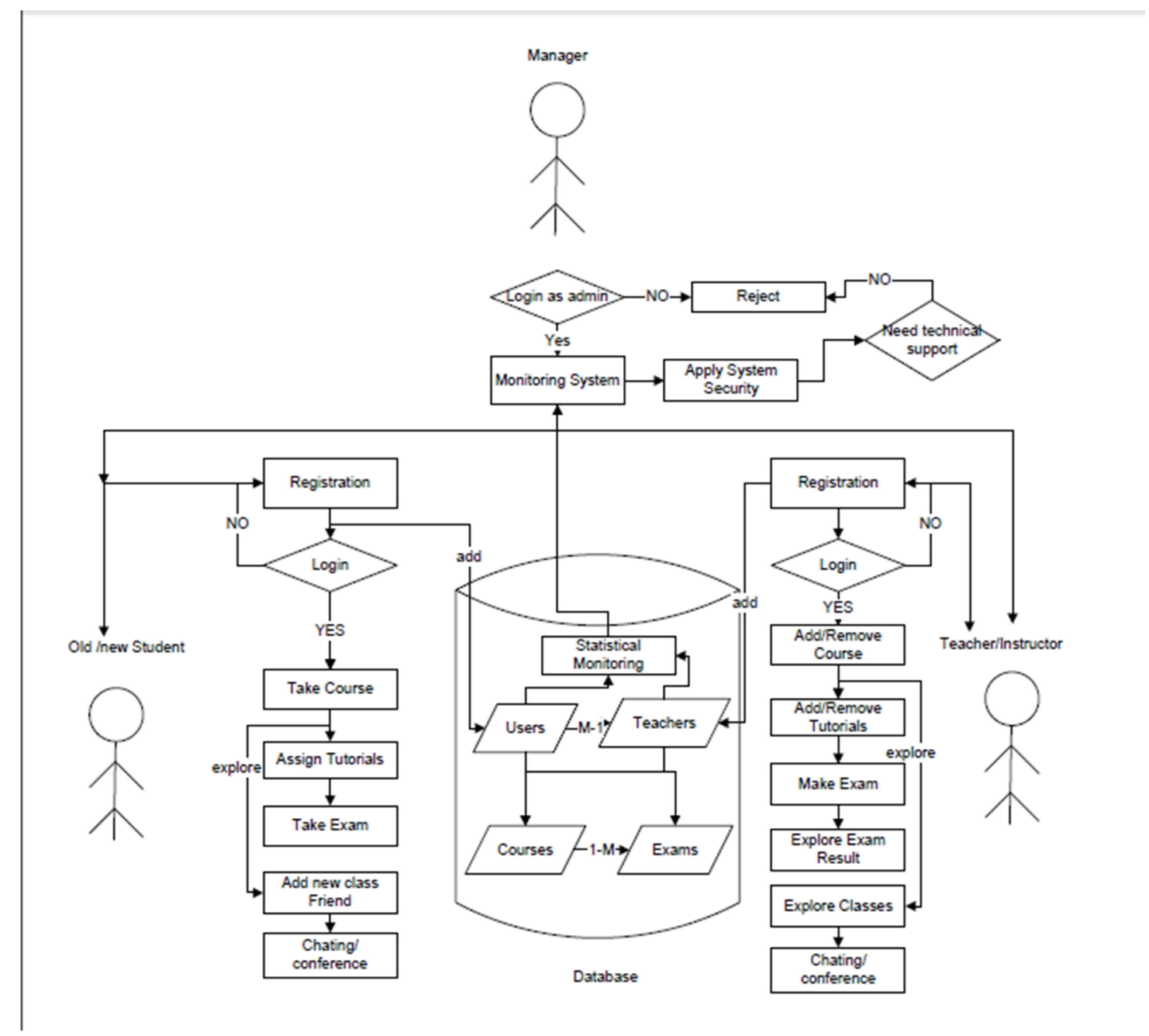

Fig. 3. Proposed Social E-learning Framework

\subsection{Proposed Algorithms}

\subsubsection{Classification Graph}

Nodes which control our framework are actors such (student, teacher, courses). Every node has one or more relations with other node. The strength of relation is calculated by graph classification techniques. (Figure 4) shows social e-learning concept graph. We suppose case study of 3 students, 3 courses and 3 teachers which I means number as $(1,2, . . \mathrm{n})$ and cursors means relations and nodes $\mathrm{S}$ means Student, $\mathrm{C}$ means Courses and $\mathrm{T}$ means Teachers.

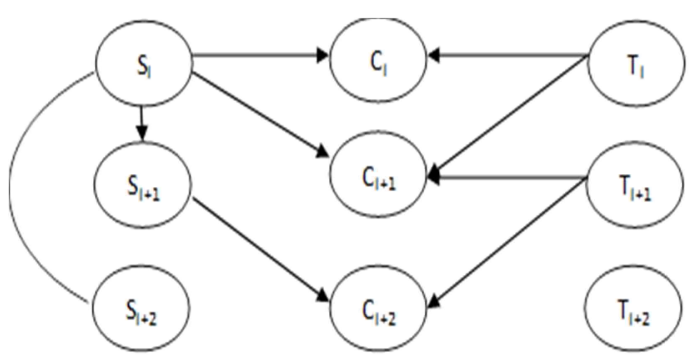

Fig. 4. The Graph of Social E-learning Concept

Every Relationship between different nodes has strength number come from matrix of this 
relationship. Relations are student's friends and favorite courses. With these relations, system can be determined which friend or course must be suggested first. From (Figure 5), we can demonstrate the following matrices of relationships in order to classified friends or courses and therefore enhance e-learning.

First, the friend relationship matrix $=$

$$
\begin{array}{cccc} 
& \mathbf{S i} & \mathbf{S i}+\mathbf{1} & \mathbf{S i + 2} \\
\mathbf{S i} & \mathbf{S i + 1} \\
\mathbf{S i}+2 & {\left[\begin{array}{lll}
0 & 1 & 1 \\
1 & 0 & 0 \\
1 & 0 & 0
\end{array}\right]}
\end{array}
$$

Then from this matrix, we can conclude that $\mathrm{Si}$ is friend of all students in our case study and $\mathrm{Si}+1$ will be the first suggested friend to $\mathrm{Si}+2$ because they subscribers in friendship of $\mathrm{Si}$.

First, the favorite courses relationship matrix $=\begin{array}{cccc}\mathbf{S i} & \mathbf{S i}+\mathbf{1} & \mathbf{S i + 2} \\ \mathbf{C i} & \mathbf{C i + 1} \\ \mathbf{C i}+2\end{array}\left[\begin{array}{llll}1 & 0 & 0 \\ 1 & 1 & 0 \\ 0 & 1 & 0\end{array}\right]$

Then from this matrix, we can conclude that $\mathrm{Si}+2$ has not any courses in our case study and will be the first suggested courses is $\mathrm{Ci}+1$ because $\mathrm{Ci}+1$ subscribers in friendship of $\mathrm{Si}$ and $\mathrm{Si}+1$.

\section{REFERENCES}

[1] R. Shen, F. Yang, and P. Han, A dynamic selforganizing e-learner communities with improved multi-agent matchmaking algorithm. The 16th Australian Joint Conference on Artificial Intelligence 2003, pp. 590-600.

[2] P. Turner and N. Jennings, Improving the scalability of multi-agent systems. the First International Workshop on Infrastructure for Scalable Multi-Agent Systems 2006, pp. 246262.

[3] D. O. Hebb, The Organization of Behaviour 1999.

[4] F. Yang, Analysis, Design and Implementation of Personalized Recommendation Algorithms Supporting Self-organized Communities. PhD thesis 2005.

[5] Bascsich (1997). Re-engineering the Campus with Web and related technology for the Virtual University. Paper presented at the Annual Conference on Flexible Learning on the Information SuperHighway, May 19-21, Sheffield Hallam University.

[6] Firdyiwek, Y. (2008). Web-Based Courseware Tools:Educational Technology, Jan-Feb, 2934.
[7] Weka, available at http://www.cs.waikato.ac.nz /ml/weka/ (accessed March 16), 2009.

[8] Moodle, available at http://moodle.org/, (accessed March 16), 2009.

[9] Ullman, L., Guía de aprendizaje MySQL. Pearson Prentice Hall.2003.

[10]Marcus, N., Ben-Naim, D., Bain, M.Instructional Support For Teachers and Guided Feedback For Students In An Adaptive eLearning Environment In: Eighth International Conference on Information Technology: New Generations (ITNG), 2011 Institute of Electrical and Electronics Engineers (IEEE), 2011.

[11]Azough S., Bellafkih M., Bouyakhf El H. (2010) Adaptive E-learning using Genetic Algorithms: IJCSNS International Journal of Computer Science and Network Security, VOL.10 No.7, July 2010.

[12] Romero, C. \& Ventura, S. (2007) Educational data mining: a survey from 1995 to 2005. Expert Systems with Applications. 33(1), 135146.

[13] Agrawal, R., Imielinski, T., \& Swami, A. (1993). Mining association rules between sets of items in large databases. In Proceedings of the 1993 ACM SIGMOD international conference on management of data,Washington, DC (pp. 207-216).

[14]Brusilovsky, P. and Maybury, M.T. From adaptive hypermedia to adaptive Web. Communications of the ACM, 45, 5 (2005), 31-33.

[15]Brusilovsky, P. Adaptive and Intelligent Technologies for Web-based Education. Künstliche Intelligenz, , 4 (1999), 19-25, available online at http://www2.sis.pitt.edu/ peterb/papers/KIreview.html.

[16]Brusilovsky, P., Eklund, J., and Schwarz, E. Web-based education for all: A tool for developing adaptive courseware. Computer Networks and ISDN Systems. 30, 1-7 (1998), 291-300.

[17] WebCT WebCT Course Management System, Lynnfield, MA, WebCT, Inc., 2008, available online at http://www.webct.com

[18]Melis, E., Andrès, E., Büdenbender, J., Frishauf, A., Goguadse, G., Libbrecht, P., Pollet, M., and Ullrich, C. ActiveMath: A webbased learning environment. International Journal of Artificial Intelligence in Education, 12, 4 (2004), 385-407.

[19] Soller, A. and Lesgold, A. A computational approach to analysing online knowledge sharing interaction. In: Hoppe, U., Verdejo, F. 
and Kay, J. (eds.) Artificial intelligence in education: Shaping the future of learning through intelligent technologies. IOS Press, Amsterdam, 2009, 253-260.

[20] Goldberg, David Edward (1989) Genetic algorithms in search, optimization, and machine learning, Addison- Wesley, $412 \mathrm{p}$.

[21] Azough S., Bellafkih M., Bouyakhf El H. (2009) Elearning adaptatif : modélisation des ressources et adaptation au profil de l'apprenant, Systèmes Intelligents: Théories et Applications Edités par europia Productions. ISBN:978-2-909285-55-3. pp51-68. 